\title{
MORPHOLOGICAL AND STRUCTURAL INVESTIGATION OF THE POLY(VINYL CHLORIDE) / GRAPHENE OXIDE COMPOSITES
}

\author{
LUIZA STINGESCU ${ }^{\mathrm{a}}$, CALIN CADAR ${ }^{\mathrm{b}, \mathrm{c}}$, LIVIU COSMIN COTET ${ }^{\mathrm{b}, \mathrm{c}}$, \\ LUCIAN BAIA $^{\mathrm{c}, \mathrm{d}, \mathrm{e}}$, KATA SASZET $^{\mathrm{d}, \mathrm{e}}$, KLARA MAGYARI $^{\mathrm{d}, \mathrm{e}}$, \\ ALIN GRIG MIHIS ${ }^{b, c}$, CARMEN IOANA FORT $^{\mathrm{b}, \mathrm{c}}$, MALVINA STROE ${ }^{\mathrm{a}}$, \\ ELENA MATEI ${ }^{a}$, ANDREEA NILA $^{a}$, ION ANGHEL ${ }^{f}$, MONICA BAIA ${ }^{c, d}$, \\ MIHAELA BAIBARAC ${ }^{a}$, VIRGINIA DANCIU ${ }^{\mathrm{b}, \mathrm{c},}$,
}

\begin{abstract}
The morphological and structural properties of the poly(vinyl chloride)/graphene oxide (PVC/GO) composites are reported. By the mixture of the two constituents, the PVC/GO composite membranes with a concentration of the GO sheets varying from 0 wt.\% to $0.5,1,2,3,4$ and 5 wt.\% were prepared. Using scanning electron microscopy (SEM) and the analysis of the atomic force microscopy (AFM) images we observed that as increasing the GO concentration in the PVC mass from 0 wt.\% to $5 \mathrm{wt} . \%$, the average surface roughness decreases from $235 \mu \mathrm{m}$ to $227 \mu \mathrm{m}$. Using Raman scattering, we report that as increasing the GO concentration in the PVC mass, the ratio between the relative intensities of the Raman lines situated in the spectral ranges 600650 and $2850-3000 \mathrm{~cm}^{-1}\left(\mathrm{l}_{600-650} / \mathrm{l}_{2850-3000}\right)$ increases as a consequence of the change of $\mathrm{GO}$ carbon atoms hybridization from $\mathrm{sp}^{2}$ to $\mathrm{sp}^{3}$. An increase in the number of $\mathrm{C}-\mathrm{C}$ bonds, simultaneous with the appearance of $\mathrm{O}-\mathrm{C}=\mathrm{O}$ bonds and the decrease of the chlorine concentration, when the $\mathrm{GO}$ concentration increases in the PVC weight is reported by X-ray photoelectron spectroscopy (XPS). The down-shift of the main diffraction signal from $24^{\circ}$ to $26^{\circ}$ when the $G O$ concentration
\end{abstract}

a National Institute of Materials Physics, Lab. Optical Process in Nanostructured Materials (LOPNM), 405 A Atomistilor str., Bucharest-Magurele, Romania

b Babes-Bolyai University, Faculty of Chemistry and Chemical Engineering, Department of Chemical Engineering, 11 Arany Janos str., RO-400028, Cluj-Napoca, Romania

c Babes-Bolyai University, Institute of Research-Development-Innovation in Applied Natural Sciences, 30 Fantanele str., RO-400294, Cluj-Napoca, Romania

d Babes-Bolyai University, Faculty of Physics, 1 M. Kogalniceanu str., RO-400084 Cluj-Napoca, Romania

e Babes-Bolyai University, Interdisciplinary Research Institute on Bio-Nano-Sciences, Nanostructured Materials and Bio-Nano-Interfaces Center, 42 T. Laurian str., RO-400271, Cluj-Napoca, Romania

f "Alexandru loan Cuza" Police Academy, Fire Officers Faculty, 3 Morarilor str., Bucharest, Romania

* Corresponding author: vdanciu@chem.ubbcluj.ro 
L. STINGESCU, C. CADAR, L.C. COTET, L. BAIA, K. SASZET, K. MAGYARI, A.G. MIHIS,

C.I. FORT, M. STROE, E. MATEI, A. NILA, I. ANGHEL, M. BAIA, M. BAIBARAC, V. DANCIU

increases in the PVC/GO composite mass from 0 wt. \% to $5 \mathrm{wt} \%$, confirms the incorporation of $\mathrm{GO}$ in the polymeric matrix and the modification of the original PVC sample structure. Using transmission electron microscopy (TEM), no agglomerations of the GO structures within the PVC/GO matrix contrast limit were observed.

Keywords: poly(vinyl chloride), graphene oxide, membranes

\section{INTRODUCTION}

Due to the ease of processing, low cost, good physical, chemical and corrosion properties, poly(vinyl chloride (PVC) is a widely used polymer. As estimated in the PVC market report [1], the global PVC market stood at US\$ 57.06 billion in 2015. It is expected a tremendous rise during the period from 2015 to 2021 , the revenue in this PVC market reaching to US $\$ 78.90$ billion by the end of the forecasted period of time and it is forecast to increase even more to 88.02 Billion USD by 2027 [2]. The main available products in the PVC market are flexible and rigid PVC. The flexible PVC has applications in medical equipment, signage, electrical cable insulation, plumbing, and inflatable items, while rigid PVC is used across construction sectors. However, PVC has several disadvantages such as poor processability, thermal stability and weatherability. Moreover, PVC without plasticizers or fillers is typically brittle and is not suitable in many fields [3-5].

Recently, the improvement in thermal, electrical and mechanical properties of PVC matrix with graphene derivatives has been reported in many related papers [6-9]. As filler material, graphene oxide (GO) is inexpensive, it has hydrophilic character and it contains epoxy, alcohol, carbonyl and carboxyl groups [10,11]. Additionally, GO can be homogeneously dispersed in organic solvents such as tetrahydrofuran (THF) and N,N'-dimethylformamide (DMF), which allows a good interfacial adhesion between polymer and GO, also inducing significant changes to the composite properties. Due to the lone pairs of electrons at the chlorine atom of the PVC, and respectively the dipole-dipole interaction between hydrogen and chlorine atom which can stiffen the polymer backbone, the PVC/GO composites are of particular interest. In addition, GO can interact with PVC chlorine atoms and become an active site that allows anchoring of other functional groups thus improving the properties of the composite. Deshmukh and Joshi [7] reported that the strong interaction between PVC and GO increased thermal stability of the composites. 
The objective of this work is to prepare PVC/GO composite membranes by mixing of GO with PVC dissolved in THF and DMF. The morphological and structural characteristics of the PVC/GO composites were investigated.

\section{RESULTS AND DISCUSSION}

By microscopic investigation, (Fig. 1a, b), 2D GO nanosheets with surfaces of tens of micrometers and thicknesses that reach up to atomic layer of carbon can be observed. These can build 3D structures of tens of micrometers thickness (Fig. 1c). Details about structural characterization of GO used for this study for the preparation of PVC/GO composites, including XRD, Raman, FTIR, DLS and XPS measurements, were presented in an research article published by Cotet et al. [12].

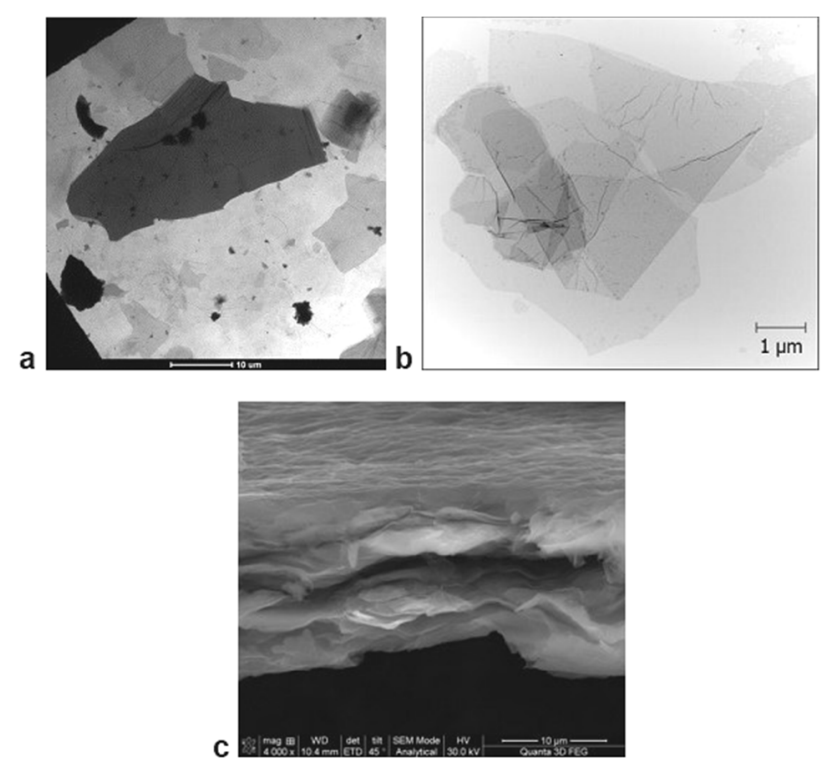

Figure 1. TEM (a), SPM (b) and (c) SEM micrographs for GO.

A selection of SEM images of PVC membranes is shown in Fig. 2. It is observed that in the case of PVC/GO composites with 3 and $5 \mathrm{wt} \% \mathrm{GO}$, the membrane surface becomes rougher, in good agreement with the observations reported in Ref. [13] and confirmed by our studies. In this context, the surface properties of the samples have been analyzed by atomic force microscopy (AFM) using the WsxM5.0 software. 
L. STINGESCU, C. CADAR, L.C. COTET, L. BAIA, K. SASZET, K. MAGYARI, A.G. MIHIS,

C.I. FORT, M. STROE, E. MATEI, A. NILA, I. ANGHEL, M. BAIA, M. BAIBARAC, V. DANCIU
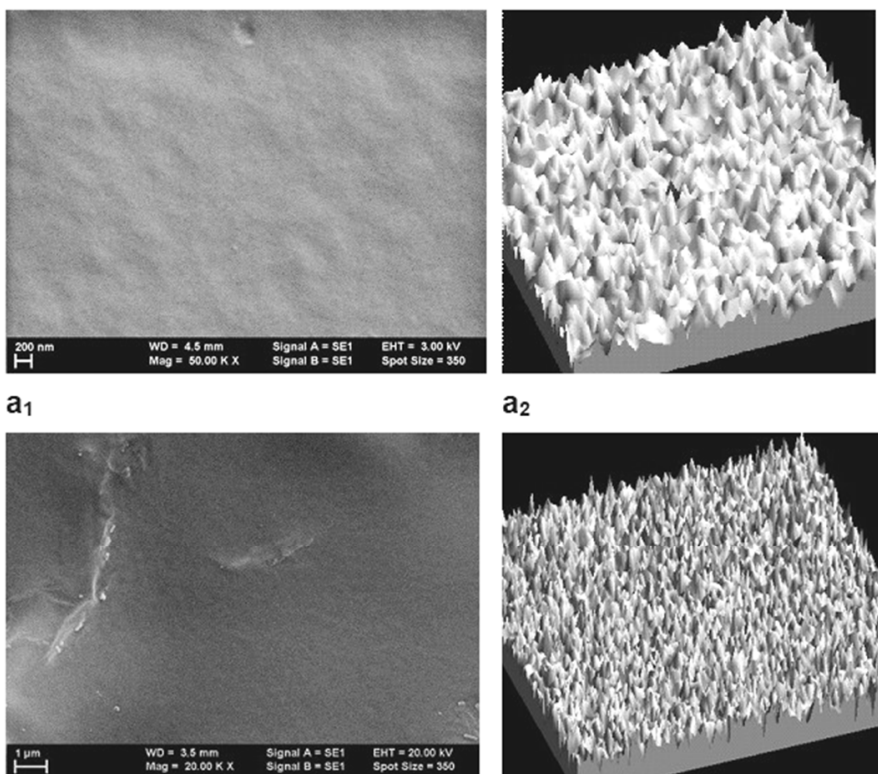

$a_{2}$

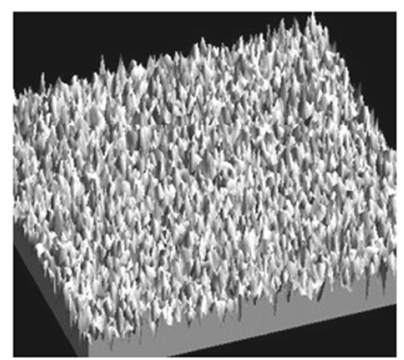

$b_{1}$

$b_{2}$
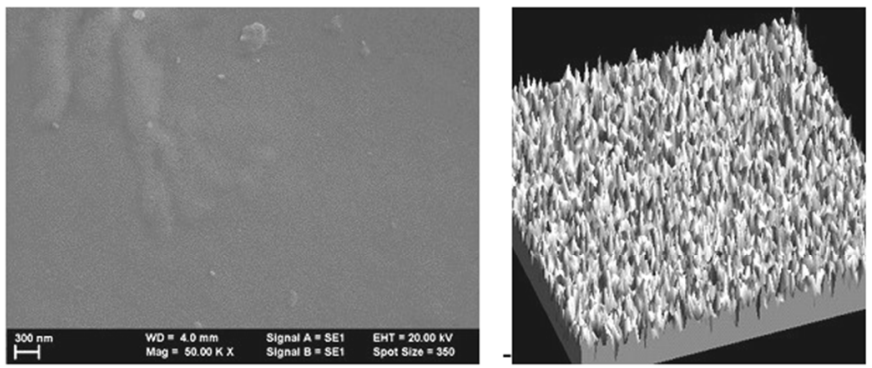

$\mathrm{C}_{1}$

$\mathrm{C}_{2}$
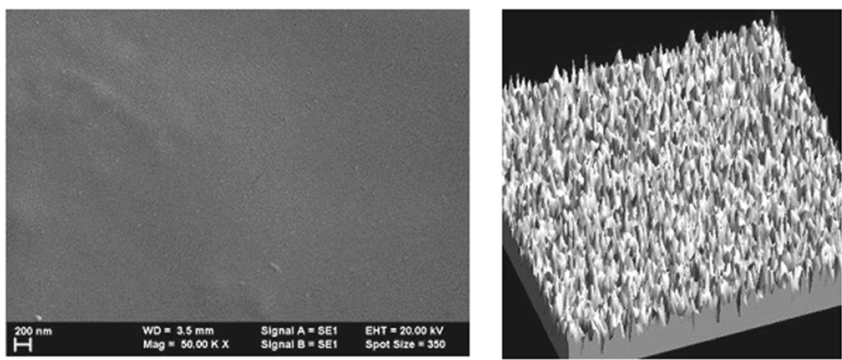

$\mathbf{d}_{1}$

$\mathbf{d}_{2}$

Figure 2. SEM images for the following membranes: PVC 0 wt.\% GO $\left(a_{1}\right), P V C$

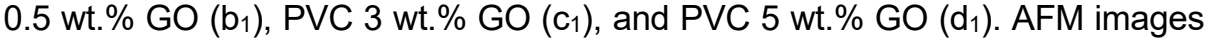
of the membranes: PVC 0 wt. $\%$ GO (a $\left(a_{2}\right)$, PVC 0.5 wt. $\%$ GO $\left(b_{2}\right), P V C ~ 3$ wt. $\%$ GO $\left(\mathrm{c}_{2}\right)$, and PVC $5 \mathrm{wt} . \% \mathrm{GO}\left(\mathrm{d}_{2}\right)$. 
From AFM images the following values for roughness average and Root Mean Square (RMS) roughness are reported: i) $235 \mu \mathrm{m}$ and $281 \mu \mathrm{m}$ in the case of the PVC membrane; ii) $233 \mu \mathrm{m}$ and $278 \mu \mathrm{m}$ in the case of the PVC membrane having 0.5 wt. \% GO; iii) $230 \mu \mathrm{m}$ and $277 \mu \mathrm{m}$ in the case of the PVC membrane having $3 \mathrm{wt} . \%$ GO and iv) $227 \mu \mathrm{m}$ and $275 \mu \mathrm{m}$ in the case of the PVC membrane having $5 \mathrm{wt} \%$ GO.

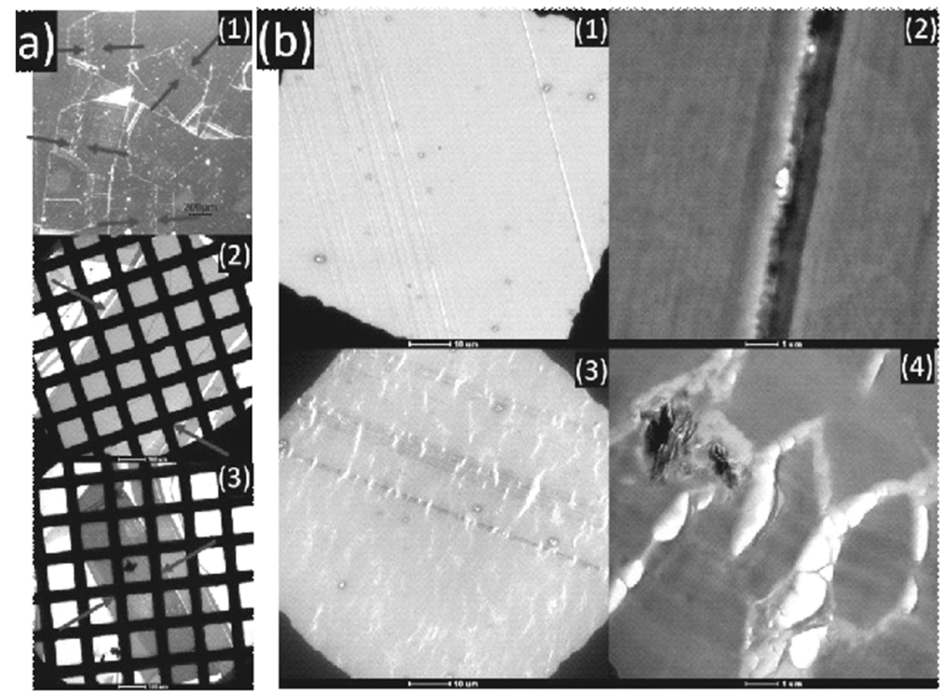

Figure 3. (a) Optical microscopy and TEM micrographs showing transversal cross-sections of (1) PVC 3 wt.\% GO, (2) PVC 0 wt.\% GO and (3) PVC 4 wt.\% GO membranes with the membrane-resin boundary indicated with arrows. (b) Textural particularities induced by the presence and absence of GO filler as observed in the multi-scale TEM micrographs for (1-2) PVC 0 wt.\% GO and (3-4) PVC 4 wt.\% GO.

In order to gain a deeper understanding regarding the $\mathrm{GO}$ dispersion in the PVC matrix, a cross-sectional analysis was performed as presented in Fig. 3. Slices of the resin embedded membranes were investigated using optical microscopy and TEM. The cross-section of the PVC sample reveals a homogeneous aspect with some texture imperfections given by the irregularities of the glass blades used during sample sectioning. The sample containing GO indicates some additional features presented as microscale discontinuities, probably even more emphasized by the mechanical stress induced during the sample sectioning. Moreover, the observed irregularities found in the analyzed sections of the PVC 4 wt.\% GO indicate a homogeneous distribution 
at the microscale. At larger magnifications, morphological features specific to both individual and agglomerated graphene sheets are observed in the intimate vicinity of the irregularities. The results suggest that GO disperses throughout the entire volume of the membrane leading towards the formation of a nano-scale network. The parameters of the GO filler-based network (i.e. connectivity and percolation threshold) are considered to be strongly correlated with the synthesis parameters and filler concentration and to further influence the electric and thermal properties of the composite.

The FTIR spectra of the PVC samples and the PVC/GO composites are shown in Fig. 4.

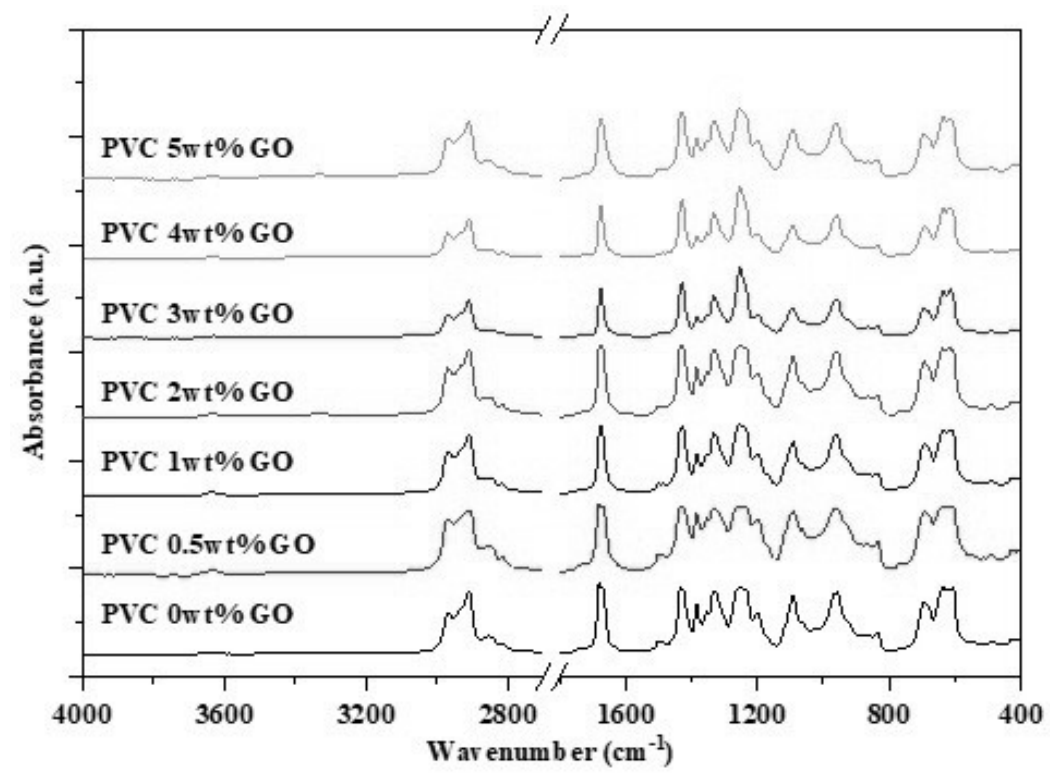

Figure 4. FTIR spectra of PVC and the following PVC/GO composites: PVC 0.5 wt. \% GO, PVC 1 wt. \% GO, PVC 2 wt.\% GO, PVC 3 wt.\% GO, PVC 4 wt.\% GO and PVC 5 wt.\% GO wt.\%.

The absorption bands from $2981 \mathrm{~cm}^{-1}$ are attributed to the stretching vibration of the $\mathrm{C}-\mathrm{H}$ bond, those from $2822 \mathrm{~cm}^{-1}$ to the asymmetrical stretching vibrations, and those from $1668 \mathrm{~cm}^{-1}$ to the stretching vibration of $\mathrm{C}=\mathrm{O}$, which are attributed to $\mathrm{CO}_{2}$ from the background. At the absorption band at $1426 \mathrm{~cm}^{-1}$, the deformation vibrations in plane of the $\mathrm{CH}$ groups can be identified, at $1340 \mathrm{~cm}^{-1}$ those of the deformation in plane of $\mathrm{CH}_{2}$, and at $1251 \mathrm{~cm}^{-1}$ the twisting vibrations of the $\mathrm{CH}$. [14] At the same time, at $1091 \mathrm{~cm}^{-1}$, the stretching 
vibrations of the $\mathrm{CH}_{2}-\mathrm{Cl}$ groups are observed, at $970 \mathrm{~cm}^{-1}$ the rocking vibration of the $\mathrm{CH}$ in the cis position, at $695 \mathrm{~cm}^{-1}$ the stretching vibration of the $\mathrm{C}-\mathrm{Cl}$, at $614 \mathrm{~cm}^{-1}$ elongation vibrations of $\mathrm{C}-\mathrm{Cl}$ and at $612 \mathrm{~cm}^{-1}$ rocking vibrations of $\mathrm{CH}$ in trans position were identified. [14] The absorption bands related to PVC have been identified being consistent with the results found in related studies. Analyzing the spectra of the composites, the specific PVC bands, but no significant differences between the spectra can be observed and the presence of the characteristic bands for GO cannot be identified with certainty. Therefore, this analysis shows that FTIR spectroscopic technique is not sufficiently sensitive to highlight the presence of $\mathrm{GO}$ in the used concentration range.

In all diffractograms of the samples presented in Fig. 5 one large and two smaller, broad signals can be observed, suggesting the amorphous structure of the materials $[14,15]$. In the case of pure PVC, these signals appear at $2 \theta \sim 18^{\circ}, 24^{\circ}$ and $40^{\circ}$, all characteristic for PVC according to previous literature. These amorphous reflections shift proportionally with the GO content, reaching $\sim 20^{\circ}, 26^{\circ}, 42^{\circ}$ in the case of PVC 4 wt. \% GO. In the case of the PVC $5 \mathrm{wt} . \%$ GO sample there is no further shifting in the reflections, the diffractogram is dominated by an amorphous signal around $2 \theta \sim 25^{\circ}$.

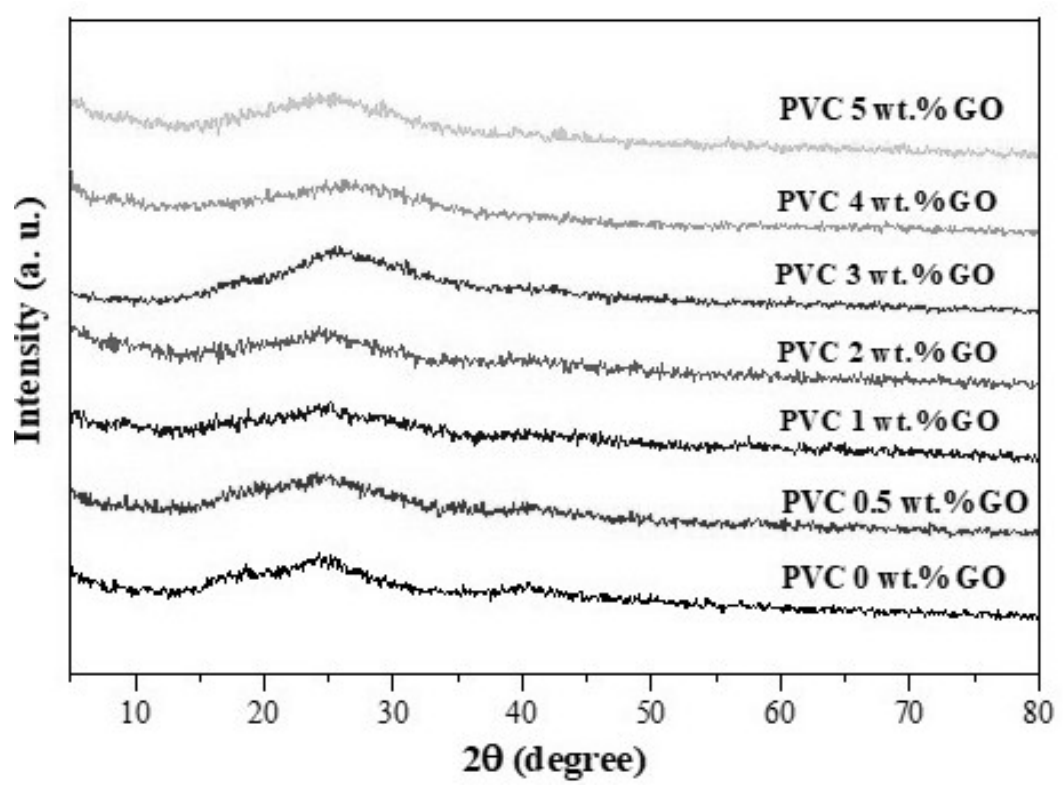

Figure 5. XRD results for pure PVC and the following PVC/GO composites: PVC 0.5 wt. \% GO, PVC 1 wt.\% GO, PVC 2 wt.\% GO, PVC 3 wt.\% GO, PVC 4 wt. $\%$ GO and PVC 5 wt. $\%$ GO. 
L. STINGESCU, C. CADAR, L.C. COTET, L. BAIA, K. SASZET, K. MAGYARI, A.G. MIHIS,

C.I. FORT, M. STROE, E. MATEI, A. NILA, I. ANGHEL, M. BAIA, M. BAIBARAC, V. DANCIU

These displacements may suggest the incorporation of GO into the polymeric matrix, that is altering the original structure of the PVC sample. The characteristic reflection of GO at $\sim 2 \theta=10^{\circ}$ cannot be clearly observed in any of the samples. [16] Apart from the shift of the above-mentioned reflections, no other significant differences were observed. This could mean that the amount of GO added in PVC/GO composites is too small to be detected by XRD measurements.

The Raman spectra of PVC and its GO composites recorded using the $514 \mathrm{~nm}$ excitation wavelength are shown in Fig. 6.

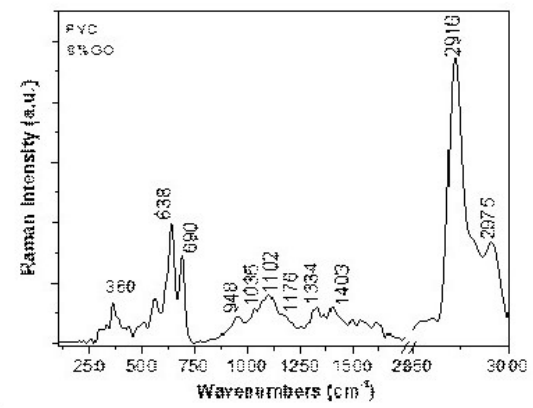

a

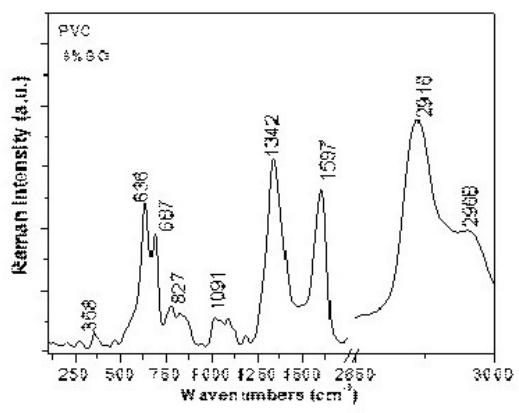

b
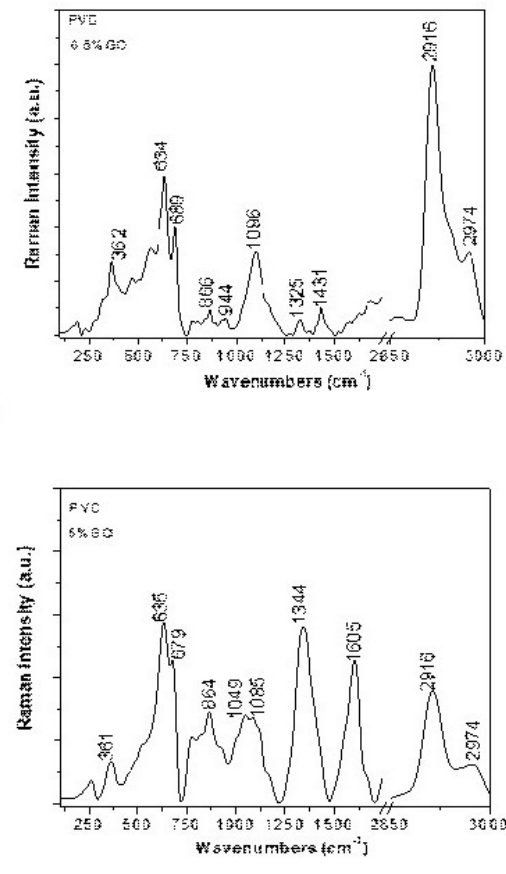

C

Figure 6. Raman spectra of the membranes: PVC 0 wt.\% GO (a), PVC 0.5 wt.\% GO (b), PVC 3 wt.\% GO (c), and PVC 5 wt.\% GO (d).

The main Raman lines of PVC are situated in the spectral ranges $300-500,600-750,950-1200,1334,1403-1430$ and $2850-3000 \mathrm{~cm}^{-1}$, being associated to the vibrational modes: $\mathrm{C}-\mathrm{Cl}$ bond in the trans configuration of the polymer, $\mathrm{C}-\mathrm{Cl}$ stretching $[17,18] \mathrm{C}-\mathrm{C}$ stretching, $\mathrm{CH}_{2}$ symmetrical stretching $\left(2915-2920 \mathrm{~cm}^{-1}\right)$ and the $\mathrm{CH}_{2}$ asymmetric stretching $\left(2970 \mathrm{~cm}^{-1}\right)$ [19]. Figure 6a 
highlights that the ratio between the relative intensities of the Raman lines in the spectral domains $600-650$ and $2850-3000 \mathrm{~cm}^{-1}\left(I_{600-650} / I_{2850-3000}\right)$ has a value equal to 0.41 . As increasing of GO concentration in the mass of the polymer, a modification of the $\mathrm{I}_{600-650} / \mathrm{I}_{2850-3000}$ ratio is observed. According to Fig. $6 \mathrm{~d}$ in the case of PVC/GO composite with a $5 \mathrm{wt} . \% \mathrm{GO}$ concentration, the $\mathrm{I}_{600-650} / \mathrm{I}_{2850-3000}$ ratio becomes equal to 1.63 . The gradual decrease of the relative intensity of the Raman line of PVC from $2916 \mathrm{~cm}^{-1}$ in the presence of $\mathrm{GO}$ indicates the generation on the macromolecular chain of PVC of some structural units of the type $\mathrm{Cl}-\mathrm{CH}=\mathrm{CH}$ - and/or $-\mathrm{CH}=\mathrm{C}-\mathrm{Cl}-$. The formation of such structural units indicates the partial dehydrogenation of the macromolecular compound which should result in the formation of new $\mathrm{C}-\mathrm{H}$ and $\mathrm{C}-\mathrm{OH}$ bonds on the $\mathrm{GO}$ surface. Formation of new $\mathrm{C}-\mathrm{H}$ and $\mathrm{C}-\mathrm{OH}$ bonds on the surface of the $\mathrm{GO}$ sheets originates in breaking $\mathrm{C}-\mathrm{O}-\mathrm{C}$ bonds from $\mathrm{GO}$ epoxy groups. In contrast with the $G O$ sheets characterized by the $I_{D} / I_{G}$ ratio equal to $0.9^{9}$, in the case of PVC/GO membrane composites having a GO concentration equal to $5 \mathrm{wt} . \%$, the $I_{D} / I_{G}$ ratio is equal to 1.23 . This higher value of the $I_{D} / I_{G}$ ratio indicates the formation of $\mathrm{C}-\mathrm{H}$ bonds as a consequence of the conversion of carbon atoms with $\mathrm{sp}^{2}$ hybridization (related to $\mathrm{C}=\mathrm{C}$ bonds) to carbon atoms with $\mathrm{sp}^{3}$ hybridization.
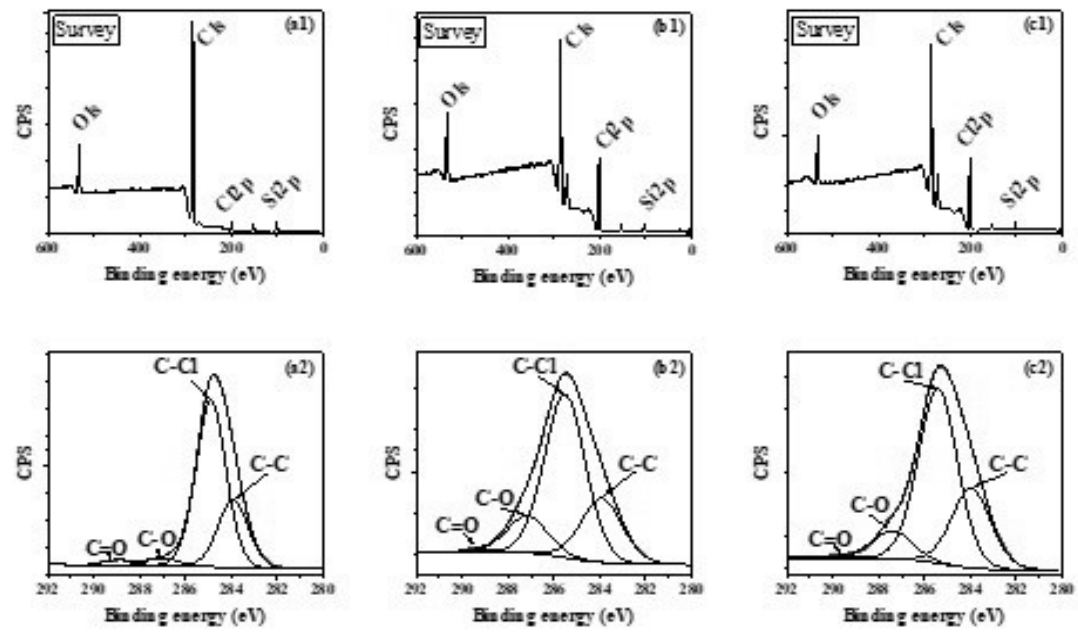

Figure 7. XPS spectrum selection, survey and C1s component (high resolution spectrum), for PVC (a1 and a2), PVC 0.5 wt. \% GO (b1 and b2), PVC 5 wt.\% GO (c1 and c2) samples. 
The XPS spectra of the PVC/GO samples and a selection thereof are shown in Fig. 7 to highlight the influence of the presence of GO in the PVC/GO composite. Based on the literature, the $\mathrm{C} 1 \mathrm{~s} \mathrm{PVC}$ line can be divided into two components, [20] at $\sim 284 \mathrm{eV}(\mathrm{C}-\mathrm{C}$ and $\mathrm{C}-\mathrm{H}), \sim 285 \mathrm{eV}(\mathrm{C}-\mathrm{Cl})$. In addition to the $\mathrm{C}-\mathrm{C}$ and $\mathrm{C}-\mathrm{Cl}$ bonds, there are also the $\mathrm{C}-\mathrm{O}$ bonds at $286.9 \mathrm{eV}(2-3 \%)$ and $\mathrm{C}=\mathrm{O} 288.5 \mathrm{eV}(2-3 \%)$. With the addition of GO (PVC with $0.5 \mathrm{wt} . \% \mathrm{GO}$ and PVC with 5 wt.\% GO) the C1s peak is modified (Fig. $7 \mathrm{~b}, \mathrm{c}$ ), suggesting that the synthesis was successful. In PVC with $0.5 \mathrm{wt} \% \mathrm{GO}$, the C-O concentration is $13 \%$ and in PVC with $5 \mathrm{wt} . \%$ GO it is $10 \%$. The analysis of the high-resolution spectrum of $\mathrm{C} 1 \mathrm{~s}$ shows that the concentration of $\mathrm{C}-\mathrm{C}$ bonds increased with GO concentration suggesting that GO covers PVC (it is clearly the change of the $\mathrm{C}-\mathrm{C}$ and $\mathrm{C}-\mathrm{Cl}$ lines intensities ratio). The XPS measurements also show a decrease in chlorine concentration with increasing GO content.

\section{CONCLUSIONS}

This work reports about new results concerning the morphological and structural properties of the composites based on PVC and the GO sheets, obtained by mixing of two constituents when free membranes were resulted. The analysis of SEM and 3D images of the prepared PVC/GO membranes highlight a roughness for all six samples, with increasing the $\mathrm{GO}$ concentration in the PVC mass from 0 to $5 \mathrm{wt} . \%$, the roughness average decreased from 235 to $227 \mu \mathrm{m}$. On the other hand, both SEM and TEM images proved that there are no agglomerations of the GO structures within the PVC/GO matrix contrast limit. XRD diffractograms revealed a down-shift of the main diffraction signal from $24^{\circ}$ to $26^{\circ}$ when the of GO concentration increases in the PVC/GO composite mass from 0 to $5 \mathrm{wt} . \%$, the fact that certified the incorporation of $\mathrm{GO}$ in the polymeric matrix and the modification of the original PVC sample structure. In the FTIR spectra no significant difference is observed between the samples, but there are differences in the Raman lines and the XPS spectra. However, the Raman spectra analysis revealed that as increasing the GO concentration in the polymer mass, the ratio between the relative intensities of the Raman lines situated in the spectral ranges $600-650$ and $2850-3000 \mathrm{~cm}^{-1}$ $\left(\mathrm{I}_{600-650} / \mathrm{I}_{2850-3000}\right)$ increases as a consequence of the change of the GO carbon atoms hybridization from $\mathrm{sp}^{2}$ to $\mathrm{sp}^{3}$. The analysis of the high-resolution XPS spectrum of $\mathrm{C} 1 \mathrm{~s}$ further showed an increase in the number of $\mathrm{C}-\mathrm{C}$ bonds, the appearance of $\mathrm{O}-\mathrm{C}=\mathrm{O}$ bonds and the decrease of the chlorine concentration as the GO concentration increased. 


\section{EXPERIMENTAL SECTION}

\section{Materials}

Natural graphite (Fluka; purum powder, $<0.1 \mathrm{~mm}$ ) powder (GF), $\mathrm{H}_{2} \mathrm{SO}_{4} 85 \%$ (SC Nordic Invest SRL, Cluj-Napoca), $\mathrm{H}_{3} \mathrm{PO}_{4} 85 \%$ (Merck), $\mathrm{KMnO}_{4}$ (Merck, 99\%), $\mathrm{H}_{2} \mathrm{O}_{2} 3 \%$ solution (SC "Hippocrates 2000" SRL, București), $\mathrm{HCl} 37 \%$ (SC Nordic Invest SRL, Cluj-Napoca), absolute ethanol (SC Nordic Invest SRL, Cluj-Napoca) were used for the synthesis of GO. Hydroxyethyl cellulose (HEC), lauryl peroxide (LPO), N,N'-dimethylformamide (DMF), poly(vinyl chloride) (PVC with $\mathrm{Mw}=48.000$, density $=1 \mathrm{~g} / \mathrm{mol}$ at $25^{\circ} \mathrm{C}$ ) used for preparation of PVC membranes and composites were purchased from the Aldrich-Sigma company, these being used without further purification.

\section{a) Synthesis of GO}

The synthesis of $\mathrm{GO}$ was based on a three-step method. In the first step $\mathrm{H}_{2} \mathrm{SO}_{4}$ and $\mathrm{H}_{3} \mathrm{PO}_{4}(83 \mathrm{~mL})$ were mixed in a 9/1 volume ratio [12, 21]. After $5 \mathrm{~min}$. of mixing, $7.5 \mathrm{~g}$ of graphite was added at room temperature under stirring. The suspension was stirred for $10 \mathrm{~min}$. and the as-prepared mixture was placed in an ice bath and after 20 min., $33 \mathrm{~g}$ of $\mathrm{KMnO}_{4}$ was added gradually, maintaining the same stirring conditions. The mixture was removed from the ice bath after $2 \mathrm{~h}$ and kept under stirring at room temperature for 2 days. In the second step, the mixture was placed again in an ice bath and $550 \mathrm{~mL}$ of $\mathrm{H}_{2} \mathrm{O}_{2}$ was added gradually under stirring. After $1 \mathrm{~h}$, the mixture was centrifuged (at $5000 \mathrm{rpm}$ for $15 \mathrm{~min}$.) and the supernatant was decanted. The remained solid material was then washed successively with $550 \mathrm{~mL}$ of $\mathrm{H}_{2} \mathrm{O}$ (bidistilled), $275 \mathrm{~mL}$ of $37 \% \mathrm{HCl}$ and $275 \mathrm{~mL}$ of absolute ethanol. The last two washes were repeated twice. During each wash, the solution was sonicated for $15 \mathrm{~min}$. (using Bandelin Sonorex ultrasonic bath, model RK-510-H; P: 160/640W; f: $35 \mathrm{KHz}$ ) and centrifuged (at $5000 \mathrm{rpm}$ for $15 \mathrm{~min}$.). In the third step, the resulting solid was dispersed in $550 \mathrm{~mL}$ bidistilled water and sonicated for $15 \mathrm{~min}$. A homogeneous dark brown suspension was obtained and kept in a sealed vessel for 5 days. Then, approximately $500 \mathrm{~mL}$ of this initial GO suspension was harvested by pipetting from the top of the vessel, poured and spread on a glass wafer and dried at room temperature. Mechanical exfoliation from the substrate was used to obtain a GO membrane (i.e. unsupported GO film). These membranes have been morpho-structurally characterized and used to obtain PVC/GO composites. 
L. STINGESCU, C. CADAR, L.C. COTET, L. BAIA, K. SASZET, K. MAGYARI, A.G. MIHIS,

C.I. FORT, M. STROE, E. MATEI, A. NILA, I. ANGHEL, M. BAIA, M. BAIBARAC, V. DANCIU

\section{b) Preparation of the membranes of PVC and its composites with the GO sheets}

To obtain the PVC membranes, $0.4 \mathrm{~g}$ PVC was dissolved in $10 \mathrm{~mL}$ THF and $10 \mathrm{~mL}$ DMF. The obtained solution was poured into a Petri dish and then deposited on a hob at $60{ }^{\circ} \mathrm{C}$ in order to evaporate the solvents. After one hour, the PVC membrane was dried under vacuum for another 6 hours until constant mass. In order to obtain PVC/GO composites, two solutions were prepared, the first containing $0.4 \mathrm{~g} \mathrm{PVC}$ in $10 \mathrm{~mL}$ THF, and the second containing 1, 2, 4, 6, 8 and respectively $10 \mathrm{mg} \mathrm{GO}$ in $10 \mathrm{~mL}$ DMF. The two solutions were mixed and then the same procedure described for obtaining the PVC membranes was followed.

\section{Characterization techniques}

X-ray diffraction (XRD) was carried out on a Shimadzu XRD 6000 diffractometer using CuKa radiation $(\lambda=1.54 \AA)$, equipped with a graphite monochromator. The diffractograms were recorded in $2 \theta$ range from $10^{\circ}$ to $80^{\circ}$ with a speed of $2 \%$ min.

IR absorption spectra were recorded with a FTIR Vertex 80 spectrometer, from Bruker, at room temperature, in the $400-4000 \mathrm{~cm}^{-1}$ range, with a spectral resolution of $4 \mathrm{~cm}^{-1}$, by using the well-known $\mathrm{KBr}$ pellet technique.

Raman spectra were recorded with a Raman spectrophotometer, T64000 model, from Horiba Jobin Yvon endowed with an Ar laser (the excitation wavelength being $514 \mathrm{~nm}$ ). The Raman spectra were recorded with a spectral resolution of $1 \mathrm{~cm}^{-1}$.

Transmission electron microscopy (TEM) investigations were performed on the GO flakes and polymer composites. The nanomaterial was dispersed in ethanol and deposited on the surface of carbon coated $\mathrm{Cu}$ grids. The composites were embedded in LR white resin and ultramicrotomed using glass blades. The slices were deposited on Cu grids for TEM investigations and on glass slides for optical microscopy studies. A FEI Tecnai G2 F20 $X$-Twin TEM operating at $200 \mathrm{kV}$ was used in bright field mode. The SEM analysis were performed using a tabletop microscope Hitachi TM4000 plus (Hitachi High-Technologies, Japan), equipped with an energy-dispersive X-ray system (AZtec One EDS, Oxford Instruments Analytical Ltd., UK), at an accelerating voltage of $5 \mathrm{kV}$.

The SEM analysis of the GO flakes was performed using a tabletop microscope Hitachi TM4000 plus (Hitachi High-Technologies, Japan), equipped with an energy-dispersive X-ray system (AZtec One EDS, Oxford Instruments Analytical Ltd., UK), at an accelerating voltage of $5 \mathrm{kV}$. 
SEM pictures of the PVC/GO composite membranes were recorded with Zeiss Gemini 500 scanning electron microscope. An analysis of the roughness parameters of these composites membranes was carried out using WSxM5.0 develop 9.3 software.

X-ray photoelectron spectroscopy (XPS) spectra were recorded with a PHI 5600ci Multi Technique system employing a monochromatic Al-Ka source (1486.6 eV), a hemispherical analyzer and charge neutralization device. Samples were carefully fixed on a double-sided carbon tape to ensure that the sample particles covered the tape. Experiments were performed by operating the X-ray source with a power of $200 \mathrm{~W}$, while the pressure in the analyzer chamber was in the range of 10-9-10-10 mbar. The binding energy scale was charge referenced to the $\mathrm{C} 1 \mathrm{~s}$ at $284.6 \mathrm{eV}$. Elemental composition was determined from survey spectra acquired at pass energy of $60 \mathrm{eV}$. High resolution spectra were obtained using analyzer pass energy of $20 \mathrm{eV}$. Analysis of the data was carried out with CasaXPS software. A Shirley background was used for all curve-fitting along with the Gaussian/Lorentzian product form (70\% Gaussian and 30\% Lorentzian).

The SPM data was processed with MountainsMap 7.4 software from Digital Surf as contact atomic force microscopy (AFM).

\section{ACKNOWLEDGMENTS}

This work was supported by a grant of the Romanian Ministry of Research and Innovation, CCCDI - UEFISCDI, project number PN-III-P1-1.2-PCCDI2017-0350 / 01.03.2018 (Graphene4Life), within PNCDI III.

\section{REFERENCES}

1. Z.M. Research; PVC Market (Rigid PVC And Flexible PVC) by Application (Pipes \& Fittings, Wires \& Cables, Films \& Sheets, Bottles and Others) For Automotive, Electrical \& Electronics, Construction, Packaging And Other EndUser: Global Industry Perspective, Comprehensive http://www.zionmarketresearch.com/report/pvc-market (accessed Dec 18, 2019).

2. John Watson (Reports And Data); Polyvinyl Chloride (PVC) Market To Reach USD 88.02 Billion By 2027 https://www.globenewswire.com/newsrelease/2020/02/13/1984885/0/en/Polyvinyl-Chloride-PVC-Market-To-ReachUSD-88-02-Billion-By-2027-Reports-And-Data.html (accessed Sep 18, 2020). 
L. STINGESCU, C. CADAR, L.C. COTET, L. BAIA, K. SASZET, K. MAGYARI, A.G. MIHIS,

C.I. FORT, M. STROE, E. MATEI, A. NILA, I. ANGHEL, M. BAIA, M. BAIBARAC, V. DANCIU

3. J. Hu; X. Jia; C. Li; Z. Ma; G. Zhang; W. Sheng; X. Zhang; Z. Wei; J. Mater. Sci., 2014, 49, 2943-2951.

4. A. Godínez-García; D.D. Vallejo-Arenas; E. Salinas-Rodríguez; S. A. GómezTorres; J. C. Ruíz; Appl. Surf. Sci., 2019, 489, 962-975.

5. F. Mindivan; M. Göktaş; Polym. Bull., 2020, 77, 1929-1949.

6. H.J. Salavagione; G. Martínez; Macromolecules, 2011, 44, 2685-2692.

7. K. Deshmukh; G.M. Joshi; Polym. Test., 2014, 34, 211-219.

8. S. Vadukumpully; J. Paul; N. Mahanta; S. Valiyaveettil; Carbon N. Y., 2011, 49, 198-205.

9. K. Deshmukh; S.M. Khatake; G.M. Joshi; J. Polym. Res., 2013, 20, 286, pp. 1-11.

10. V. Singh; D. Joung; L. Zhai; S. Das; S. I. Khondaker; S. Seal; Prog. Mater. Sci., 2011, 56, 1178-1271.

11. S. Sava; C. Sarosi; B. Stanca; A. Tonea; C. Alb; D. Dudea; Stud. Univ. BabesBolyai Chem., 2015, 60, 71-80.

12. L.C. Cotet; K. Magyari; M. Todea; M. C. Dudescu; V. Danciu; L. Baia; J. Mater. Chem. A, 2017, 5, 2132-2142.

13. S.M. Hosseini; E. Jashni; M. Habibi; M. Nemati; B. Van der Bruggen; J. Memb. Sci., 2017, 541, 641-652.

14. N. Ahmad; A. Kausar; B. Muhammad; J. Plast. Film Sheeting, 2016, 32, 419-448.

15. C. Niculăescu; L. Olar; R. Stefan; M. Todica; C.V. Pop; Stud. Univ. BabesBolyai Chem., 2018, 63, 63-70.

16. Y. Feng; C. He; Y. Wen; Y. Ye; X. Zhou; X. Xie; Y.W. Mai; Compos. Part A Appl. Sci. Manuf., 2017, 103, 74-83.

17. K.A. Prokhorov; D.A. Aleksandrova; E.A. Sagitova; G.Y. Nikolaeva; T.V. Vlasova; P.P. Pashinin; C.A. Jones; S.J. Shilton; In Journal of Physics: Conference Series; 2016; $p 012001$.

18. F. Qiu; G. He; M. Hao; G. Zhang; Materials (Basel), 2018, 11, 2139, pp. 1-15.

19. J.M. Hankett; C. Zhang; Z. Chen; Langmuir, 2012, 28, 4654-4662.

20. K. Artyushkova; J.E. Fulghum; Surf. Interface Anal., 2001, 31, 352-361.

21. A. Pérez Del Pino; E. György; C. Cotet; L. Baia; C. Logofatu; RSC Adv., 2016, $6,50034-50042$. 